\title{
Words That Go Together: Teaching Collocations in the EFL Classroom
}

\author{
Tünde NAGY \\ Sapientia Hungarian University of Transylvania (Cluj-Napoca, Romania) \\ Department of Human Sciences \\ nagytunde@uni.sapientia.ro
}

\begin{abstract}
Using the right collocations in a foreign language is often a challenge for language learners who may not be familiar with their use and characteristics. After presenting the types of collocations and the importance they have in the acquisition of a foreign language, the paper draws attention to the necessity of raising students' awareness of collocations, and at the same time it reflects on possible ways of teaching them. Focusing especially on verb-noun collocations, the paper examines the learning materials used in the EFL classes at Sapientia Hungarian University of Transylvania, Miercurea Ciuc, with special regard to the exercises on these constructions. In line with construction grammar theories (Goldberg 1995, 1997, 2006), it is assumed that collocations are to be treated as constructions, pairings of form and meaning, including patterns with different degrees of predictability. Collocations, consisting of both predictable (e.g. read a book, blue sky) and non-predictable forms (e.g. run a program, safe and sound) can be more easily remembered if regarded as constructions where all the constituent elements contribute to the meaning of the construction as a whole (but whose meaning is more than the sum of the constituent elements). In order to gain a better understanding of collocations, the use of electronic corpora and electronic databases as well as additional materials on collocations that would complement the language materials used in class is highly encouraged. By making use of these resources, students can see examples of everyday language use and become more aware of the use of collocations as well as the similarities and differences between them in different languages.
\end{abstract}

Keywords: collocations, teaching practices, corpora and electronic databases, awareness-raising

\section{Introduction}

When it comes to teaching vocabulary in foreign language classes, a common practice is to teach the meaning of words in isolation, without regard to the context 
in which a word appears. This practice, while useful in itself, does not always bring satisfactory results, especially in the case of collocations, constructions that combine two or more words of different lexical and functional categories (nouns, verbs, adjectives, prepositions) and whose constituent elements are often not interchangeable (in the case of restrictive collocations). An important aim of this paper is to draw attention to the importance of raising students' awareness of the co-occurrence of words in a language and to show how introducing additional teaching materials as well as electronic resources in the classroom can serve this purpose. It is assumed that the passive (recognizing the presence of collocations in a text) and the active knowledge of collocations (the ability to reproduce them) should be given equal attention. After presenting the types of collocations and the importance they have in foreign language acquisition, the paper will explore some ideas on how collocations could be presented in class in a suitable way. While teaching collocations is important in all language combinations, the main focus in this paper will be placed on teaching English collocations to bilingual Hungarian-Romanian students.

\section{Defining collocations}

Due to the complex nature of collocations (having varying degrees of predictability, consisting of two or more elements belonging to different parts of speech, in most cases with adjacent elements (yet not always - consider he kept his terrible promise..., where terrible is inserted in the construction (Schmid 2003: 241)) and cultural differences (e.g. the collocation bread and butter has a larger semantic field in English than in Hungarian, referring both to food and one's means of subsistence), the notion of collocation is hard to pin down. The term itself can be dated back to Palmer (1954), who is the first to introduce the term "collocation" in his dictionary, A Grammar of English Words, as well as to the work of Firth (1957: 196), who talks about "meaning by collocation", which he sees as lexical meaning at the syntagmatic level. Distinguishing between paradigmatic relations of words (words belonging to the same class) and syntagmatic relations (words combining with words belonging to other parts of speech), Firth understands lexical meaning as the ability of a specific word to collocate with other words. In Firth's view, collocation is "the company a word keeps" (Firth 1957: 11). Later approaches to collocations pick up on the ideas expressed both by Palmer (1976) and Firth (1957); among the numerous definitions, we can mention that of Leech (1974: 20), according to whom collocative meaning is "the association a word requires on account of the meaning of words which tend to occur in its environment", or that of Hoey (1991: 6-7), who sees collocations as "the relationship a lexical item has with other items that appear with greater than random possibility in (its) textual 
context". While there are many collocations that contain two co-occurring lexical items (e.g. rancid butter, heavy rain), a collocation can consist of several items, just as Sinclair (1991: 170) notes, defining collocations as "the co-occurrence of two or more words within a short space of each other in a text".

From a semantic point of view, collocations are made up of two parts: the base that bears most of the meaning of the construction and that selects a collocator (McKeown and Radev 2000). To illustrate the presence of the base and that of the collocator, we can say that in the collocations give a lecture or deliver a lecture, for example, lecture is the base, and this then selects the collocators give and deliver or another collocator, e.g. present (present a lecture). While in some cases a base can select several collocators, as has been the case in the previous example, in the case of more restrictive collocations, the base only triggers the use of one specific collocator: e.g. in the construction commit a suicide, suicide as the base can only select the collocator commit. In some other cases, the collocator itself can be semantically empty; so, for example, in the construction take a bath, take does not give any additional meaning to the construction other than have (McKeown and Radev 2000). Collocations are often included in the same category with idioms. Nevertheless, in spite of the similarities they share, they are also different. An important characteristic that differentiates collocations from idioms is their compositionality: idioms are non-compositional, unanalysable constructions, whereas collocations, though to some degree non-compositional and often lacking semantic transparency (Taylor 2017) (e.g. running a business does not have anything to do with running), are more analysable semantically than idioms are.

Collocations can represent a free or more restricted combination of words, with a weak, medium, or strong bond between the constituent elements. While in the case of free combinations the parts are interchangeable with slight difference in meaning or style (e.g. give, deliver, present all collocate with lecture), other collocations are more restrictive - for example, take a picture vs * make a picture, speak or tell the truth vs * say the truth. Regarding the morpho-syntactic properties, collocations pertain to two major groups, lexical and grammatical collocations, depending on the part of speech the constituent elements belong to (Benson, Benson, and Ilson 1986). The first category contains a variety of combinations, such as verb + noun, e.g. make a promise, adjective + noun, e.g. strong tea, noun + verb, e.g. plane takes off, noun + noun, e.g. child care, adverb + adjective, e.g. hopelessly devoted, verb + adverb, e.g. argue heatedly. Different from lexical collocations, grammatical collocations often contain a noun, a verb, or an adjective proceeded or followed by a preposition such as at night, extend to, be interested in or a to-infinitive construction such as be inclined to do something.

Concerning lexical collocations (and, more specifically, verb-noun collocations) in English, Romanian, and Hungarian, the differences between them often become apparent. Apart from cases when the collocation is the same 
in these languages (e.g. keep in mind, a ține minte in Romanian, észben tart in Hungarian), collocations often differ from each other due, among other things, to the high amount of preverbs in Hungarian - consider, for example, keep your word, a-şi ține cuvântul in Romanian, betartja a szavát in Hungarian; the different requirements for case, e.g. play a musical instrument (accusative case), a cânta (sing) la un instrument (different verb + dative case) in Romanian and hangszeren játszik (musical instrument in superessive case) in Hungarian (Hungarian has 27 cases), etc. The similarities between English and Romanian with regard to vocabulary on the one hand and the distinctiveness of Hungarian (as part of the Uralic language family) on the other hand often come into view. Examples are, for instance, collocations with hot verbs, such as make (a face in Romanian, csinál, készít in Hungarian), e.g. make time for something with the same construction in Romanian, a face timp pentru ceva, whereas in Hungarian the construction is different: idót szakít valamire; similarly, we have make friends, a-şi face prieteni in Romanian but barátokat szerez in Hungarian or make a promise, a face o promisiune in Romanian but ígéretet tesz in Hungarian or keep (a tine, a păstra in Romanian, (meg)tart in Hungarian), e.g. keep score - a ține scorul in Romanian, jegyzi az eredményt in Hungarian, keep a journal - a ține un jurnal in Romanian but naplót ír in Hungarian, keep quiet, a ține gura/a păstra tăcerea in Romanian, csendben maradni in Hungarian, etc. Generally speaking, it can be said that due to the similarities between English and Romanian, HungarianRomanian bilinguals with a good knowledge of Romanian may have it easier when it comes to the acquisition of collocations. While the influence of L1 and L2 on the acquisition of collocations would be a very interesting topic to analyse, it falls beyond the scope of this paper.

\section{Collocations and foreign language acquisition}

Several studies suggest that learners are generally quite slow at acquiring productive knowledge of L2 collocations (e.g. Durrant and Schmitt 2010, Laufer and Waldman 2011, Li and Schmitt 2010, Nekrasova 2009, Yamashita and Jiang 2010). Boers et al. (2014) draw attention to the fact that L2 learners produce word combinations that sound odd to native speakers (e.g. * do a mistake; * say the truth; *make a dream). Similarly, Faghih and Sharafi (2006) investigating the use of collocations by Iranian language EFL learners find that most of the errors learners make in their productions are rooted in their lack of proficiency in collocations, and Bahns and Eldaw (1993) note that the knowledge of collocations lags behind the knowledge of general vocabulary. An interesting observation is made by Demir (2017: 75) who argues that as learners progress to intermediate levels they tend to make fewer collocational errors; nevertheless, their knowledge 
of collocation stagnates as they are still dependent on the prefabricated routines they have acquired before.

The correlation between language proficiency and the knowledge of collocation has been pointed out by many experts in the field (e.g. Zhang 1993, Sung 2003, Keshavarz and Salimi 2007). By analysing texts of native and non-native speakers of English, Waller (1993) remarks that EFL learners' deviant use of collocations is the most tangible marker of their non-nativeness. The reason for this might be, as Kjellmer (1991) notes, the fact that native speakers use large prefabricated sections, whereas language learners use bricks rather than strings of words as their language material, having automated few collocations.

The reduced and sometimes unusual use of collocations by EFL learners can be attributed to several causes. Besides a possible negative transfer from L1 and/ or L2, students are often not made aware of the presence of collocations in a language. This is in line with Begagic and Dubravac's (2014) observation, who list as possible explanations for this deficiency the negative transfer from L1, students' unawareness of collocations in their process of language learning, and also the fact that students are mostly taught grammar rules. That awareness plays an important role in the language learning process is a leading thought of many studies (Ramirez 2012, Fan 2009, Lewis et al. 2000). According to Ramirez (2012), the strategy of noticing fosters performance and accuracy in language production. Thornbury (2002) goes even further by stating that there is no acquisition without noticing. This line of thought is in compliance with Schmidt's (2001) noticing hypothesis, which considers noticing as a first crucial step for language structures to be retained in memory. With regard to foreign language teaching, Ellis (1997) proposes that teachers should make students familiar with the method of noticing by providing them with strategies to use outside the classroom.

While learner's attention may be attracted to a certain linguistic structure without external intervention (the teacher), this rarely happens because of several reasons. One of them, as Wray (2002) notes, is that post-childhood language learners tend to view and learn words separately instead of multiword chunks. Adult learners are used to seeing words separated by white spaces, and so they are inclined to learn them in isolation. Another cause is salience, which refers to the novelty a certain construction bears to the learner. Eye-tracking experiments have shown that learners look at the construction unknown to them for a longer period of time than at words they are familiar with (Godfroid, Housen, and Boers 2013 as cited by Boers et al. 2014). The novelty effect of a construction is often reduced by the fact that many collocations contain hot verbs (e.g. get, take, have) or frequently used function words. As a consequence, even if a combination of words contains a word that the learner is not familiar with, due to the presence of a frequently used word the importance of the collocation as a phraseological unit is often overlooked. This is especially true in the case of verb-noun collocations 
where it is the noun that carries most of the meaning of the construction (e.g. have a discussion, make an assumption, do business). Finally, the lack of perceptual salience, attributed to the fact that frequent linguistic structures (especially prepositions, articles, and auxiliaries) are often phonetically reduced in the stream of discourse (Bybee 2002) makes it harder for language learners to perceive the right word. The fact that several collocations contain an element that has a phonological neighbour, sharing every phoneme except for one (e.g. make a photo instead of take a photo), can also partly explain why learners often err in their word choices.

Taking all this into account, it is assumed that incidental learning is likely to occur only in cases when constituents of a collocation are new to the learner (Boers et al. 2014). Bearing in mind the great variety and complexity (transparency vs non-transparency) of collocations, it is essential that more attention be given to them in foreign language classes. In what follows, the paper will look at the language books used in EFL classes at Sapientia Hungarian University of Transylvania, Miercurea Ciuc (henceforth Sapientia University) and address the question of what other resources and additional materials would be suitable for teaching collocation to language learners.

\section{Language books used in the EFL classroom}

The language books currently used in the EFL classroom at Sapientia University are the New English File series, edited by the Oxford University Press, having young adult learners as the target group. They comprise 6 levels (beginner, elementary, pre-intermediate, intermediate, upper intermediate, and advanced) and consist of a student's book, a workbook (which follows the content of the student's book), and also a teacher's book. Taking into consideration the fact that students entering the university already have some knowledge of English, the beginner level is not used in class; similarly, the advanced level is used to a lesser extent since the number of students having a proficiency level of English is relatively low. The paper intends to analyse the content of these series with regard to the presence of collocations in the student's books and workbooks. While it focuses primarily on verb-noun collocations, it also looks at other lexical collocations as well as grammatical constructions. It should be noted that these series also include additional online materials suitable for self-study, yet they do not constitute a part of the present analysis.

The New English File book series contain interesting lessons on a wide range of topics, appropriate to the field of interest of young adult learners. The reading and listening exercises often focus on real life experiences or reports about wellknown people (sportsmen, actors, etc.) students can relate to; in addition, the 
lessons include interactive speaking exercises. Each unit has a What do you remember? section where students can test their knowledge on what has been covered in that specific unit.

While these language books constitute a good teaching material, when it comes to teaching collocations, a few shortcomings become apparent. By thoroughly analysing the content of both the student's books and workbooks, the relative lack of collocation exercises (especially lexical collocations) is noticeable. Collocations can be found starting from the elementary level, where there are several exercises containing lexical - and among them verb-noun - collocations (the main focus of attention of this analysis). It seems, however, that besides collocations related mainly to everyday activities and containing hot verbs, such as get, have, and take, other verb-noun collocations are relatively few, and when they do occur they are not highlighted at all. While the introduction of these collocations might suffice for the elementary and pre-intermediate levels, higher-level students should be made familiar with other verb-noun collocations as well. In fact, except for one shorter section in the upper intermediate book (p. 85), where attention is drawn to collocations (introducing them together with idioms), no reference is made to the existence of such constructions. Another shortcoming of this series has to do with the type of vocabulary exercises. Generally, it can be said that the book series contains a fair amount of vocabulary exercises, among which also several examples of collocations can be found. Nevertheless, these exercises are usually of the similar type such as matching the constituent elements of collocations, matching phrases, filling in the missing word, or giving the opposite of a given construction. The type of exercise that outnumbers the rest is where the missing word (usually a verb) has to be filled in (see Figure 1). There are relatively few cases where students can see the collocations in their entirety, wherefore recognizing and treating these elements as collocations would require extra effort on the part of language learners. The same applies to the reading exercises in these books, where apart from a few highlighted examples of collocations (where both elements of a collocation are highlighted) it is mostly individual words that are put in the foreground.

Verb phrases. Complete the verb phrases.

make your bed

\begin{tabular}{ll}
\hline do pick up take out tidy waste \\
\hline \\
your room \\
things from the floor \\
the rubbish \\
the washing up \\
time
\end{tabular}

Figure 1. Exercise on collocations (New English File, Pre-Intermediate, p. 50) 
Regarding the presence of multi-word constructions, there are several exercises in higher-level books (intermediate, upper-intermediate, and advanced levels) focusing on phrasal verbs, prepositional verbs, and phrasal-prepositional verbs. It can be said then that lexical collocations are only moderately present in this series, whereas grammatical collocations are more in focus. In order to correct this shortcoming, it is essential that students be given additional materials on collocations and be introduced to resources (including electronic databases) that facilitate the acquisition of such constructions.

\section{Teaching collocations in the EFL classroom}

In order to become more aware of the presence of collocations in a language, students should have the opportunity to observe these constructions in context and also to use them frequently in different activities. Despite that vocabulary exercises are included in each unit of the New English File book series, they do not show great variety. In addition, as it has been pointed out above, the number of activities that highlight collocations in their entirety is quite low, so students are often required to match the constituent elements of collocations or fill in a missing word. As a consequence, they may not regard collocations as constructions or recall them as such. It is beyond dispute that such exercises improve students' vocabulary; nevertheless, seeing collocations in their entirety would raise the chances of a more thorough understanding of these constructions.

In light of the above, it is considered that the exercises in these books (and possibly other language books) should be completed with additional materials that focus on collocations in their entirety, treating them as constructions. In what follows, examples will be given of exercises that are suitable for teaching collocations in EFL classes; the language books referred to are Oliveira 2013 (from pre-intermediate level upwards), Marks and Wooder 2007 (from pre-intermediate level upwards), O'Dell and McCarthy and O'Dell 1999 (elementary level), and also O'Dell and McCarthy 2008 (advanced level). All these books contain a variety of topics (e.g. appearance, character, feelings, houses and apartments, eating habits, movies/books, sports, computer, academic English, work, business, money, travel, weather, etc.), are user-friendly (collocations are highlighted, and in some cases a synonym is given or the collocation is explained briefly), and can be used both in the classroom and as self-study. They are useful in different respects: Oliveira's 1000 English Collocations in 10 Minutes a Day (2013) starts each unit with a short story or explanation, including many useful collocations. Marks and Wooder's Check Your Vocabulary for Natural English Collocations (2007) contains a variety of exercises ranging from matching parts of collocations, crosswords, looking for the opposite of a certain expression, choosing the most 
natural collocation, correcting mistakes, choosing between two alternatives (e.g. make or do), ordering jumbled letters to speaking activities where language learners have to answer questions with collocations. Similarly, McCarthy and O’Dell's English Vocabulary in Use (elementary) (1999) is a good introduction to collocations, containing, on the one hand, expressions with hot verbs (e.g. have, go, come, take, bring) and also grammatical constructions with conjunctions and prepositions, while, on the other hand, concentrating on topics that are useful for learners at this level (e.g. everyday activities, movement, family, birth, marriage and death, parts of the body, clothing, describing people). An important strength of this book is that it introduces collocations within subpoints of a specific topic (e.g. within the topic of Health and Illness: How are you today? Everyday problems, Problems people have for many years, Illness in hot/tropical countries, Serious illnesses, How to keep fit and well?) that can serve as good introductory questions for speaking activities. In addition, this book also contains questions that are good for group work or pair activities and that encourage the use of collocations (e.g. What do you think is a good diet? What illnesses are connected with smoking? etc.). Some exercises also make room for creativity, especially in cases where language learners are asked to complete speech bubbles with imaginary questions or sentences. Finally, McCarthy and O'Dell's English Collocations in Use (advanced) (2008), targeting advanced learners, points out the different connotations of collocations (formal, informal use and also positive, negative connotation) and also draw attention to possible common errors related to their use (e.g. * make research instead of do research).

The following items taken from different exercises are good examples of how collocations can be practised in EFL classes. They are taken from the books mentioned above.

1. Choose the correct word to complete the collocations:

The process of creating friendships is called....

a) getting friends b) earning friends c) making friends (Oliveira 2013: 6)

2. Choose the best word or phrase to complete these sentences. Other collocations are in bold type:

Before he left the house, he the fire and raked over the embers.
a. put out
b. turned out
c. stopped

(Marks and Wooder 2007: 48)

3. What's the opposite of these expressions?

straight hair/_hair____ (Marks and Wooder 2007: 2)

4. Complete the two-word expression using the jumbled letters.

knife and KORF

(Marks and Wooder 2007: 3) 
5. Which of these expressions is not possible to complete the sentence?

The dog was running

a. side to side b. round and round in the park.

(Marks and Wooder 2007: 7)

c. up and down

6. Which is not a natural sounding collocation?

The train London at 10.35 .
a. gets to
b. gets into
c. arrives in
d. arrives at

(Marks and Wooder 2007: 8)

7. Which of these two versions sounds more natural?

He's travelled far and wide.

He's travelled wide and far.

We've been there and here.

We've been here and there.

(Marks and Wooder 2007: 7)

8. House or home? Complete the sentences with the correct word:

I'm going to move next week, so I'll give you my new address.

(Marks and Wooder 2007: 17)

9. Correct the mistakes in the underlined expressions.

We did cycling this weekend.

(Marks and Wooder 2007: 37)

10. Complete the expressions:

A flock of

A swarm of

A heard of

(Marks and Wooder 2007: 40)

11. What is the person saying in the picture?

12. Ann and Bill meet in a bar. Bill usually says the wrong things. Correct his mistakes!

13. Write a conversation using as many as possible of the phrases from the opposite page.

(Mc Carthy and O’Dell 1999: 75)

Due to their variety, these types of exercises offer a good insight into the nature and use of collocations. As they encompass a wide array of topics, they can be easily implemented as additional materials in the EFL classroom, both at higher and lower levels. By containing a high number of collocations that are frequently highlighted, these exercises can help language learners become more aware of the presence of word combinations as well as the context they appear in.

Apart from these exercises, another important means of making students familiar with the use of collocations is to introduce them to electronic corpora and other electronic databases. This is especially true in the case of advanced learners who already have a good knowledge of English but are rather unsure when it comes to the use of collocations. While it often requires some extra effort to use electronic corpora in class due to several factors (lack of time or possibility to use computers in class, the need to follow a certain curriculum, etc.), it is assumed 
that students will remember and understand collocations more easily if they search for them in an electronic corpus or database. A possible way of applying corpus linguistic methods is by adopting the exploratory approach as understood by McCarthy (1998), also called the "three I-s" - illustration, interaction, and induction -, where illustration refers to looking at real data, interaction to discussing the findings with others, and finally induction implies formulating conclusions based on the findings. According to this approach, after looking up specific constructions in a corpus, students could talk about the findings among themselves (e.g. as part of a group work) and also try to formulate deductions regarding the frequency of a certain word combination, the context in which it appears, and the connotations it can have (negative/positive, formal/informal).

\section{Collocations and corpus linguistics}

An important advantage of corpus linguistic methods is that they offer natural language data and can show the larger context of a specific word or construction. With the help of concordance programs that turn electronic texts into databases, it is possible to look up any word, parts of words as well as word combinations. Specific features can show the collocates of a particular word (the collocates option) and also highlight and centre a collocation, showing its context (KWIC - key word in context option). In addition, concordance programs can show the frequency of a word or word combination and can also indicate the specific field (documentaries, reports, political documents, law, medicine, etc.) a construction is used in. As such, corpus analysis allows both for a qualitative (showing a specific construction in context) and a quantitative (showing its frequency) interpretation of findings.

There are many varieties of corpora that can be used for this purpose, among them written corpora (e.g. The Brown Corpus), spoken corpora (The Lancaster/ IBM Spoken English Corpus), or of a mixed type such as the British National Corpus with $90 \%$ written and $10 \%$ spoken part; there are also monolingual and multilingual corpora as well as synchronic and diachronic corpora (an example of a diachronic corpus is the Helsinki Corpus of the English Texts). Some of these corpora are freely available and can be used for several queries a day after an account is created. Such corpora are the $B N C$ (British National Corpus with around 100 million words) and Coca (Corpus of Contemporary American English with more than 560 million words). While for the study of certain rare linguistic phenomenon the COCA would yield better results, for the analysis of collocations both corpora are suitable. Below you can see the collocate display for the verb gain as found in the BNC (Figure 2) as well as the KWIC (key word in context) display of the collocation gain access in the BNC (Figure 3). 


\section{British National Corpus (BNC)}

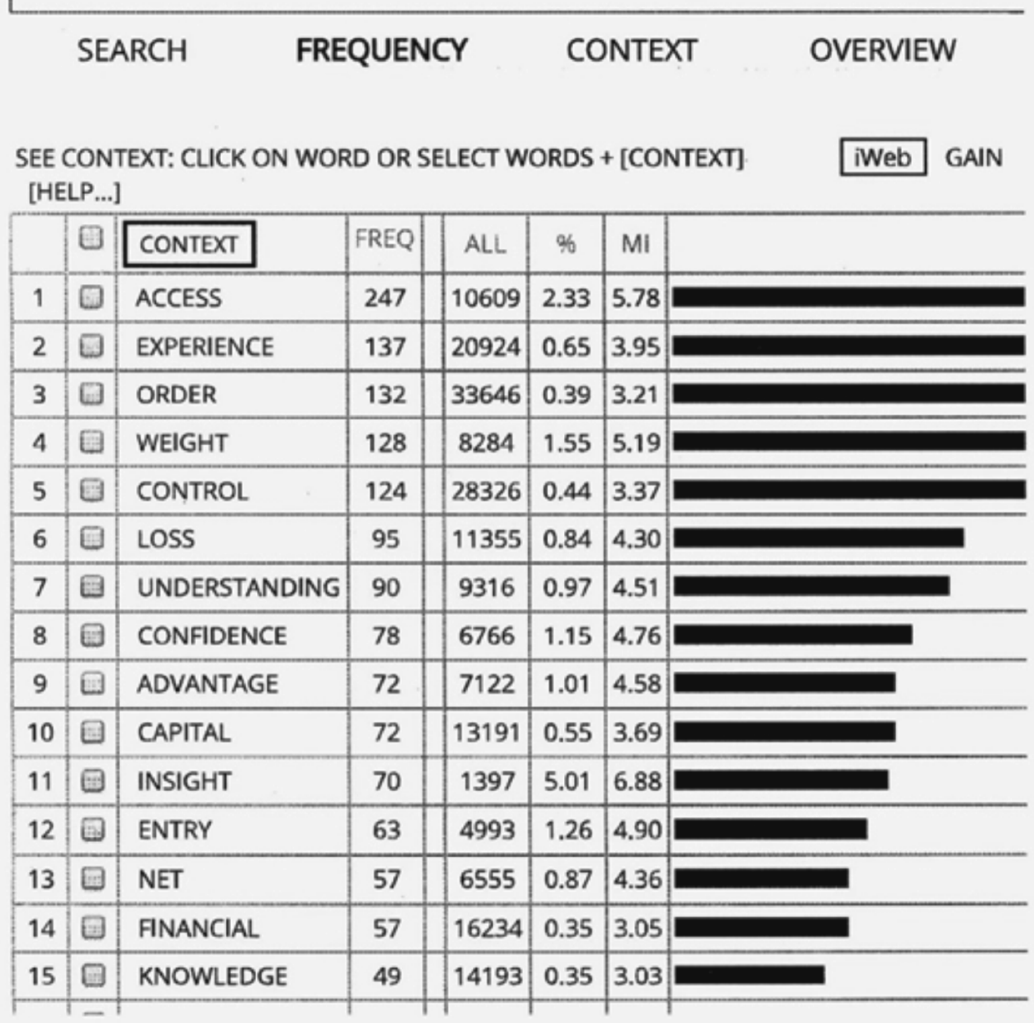

Figure 2. The collocates of the verb "gain" in the BNC corpus

In addition to using these databases, language learners can eventually make their own corpus and use it for the search of several linguistic phenomena (maybe as part of an assignment). Other databases that can foster the acquisition of collocations are online dictionaries (besides traditional ones), such as bab. la (https://en.bab.la/dictionary/), or online resources that contain collocation dictionaries, such as the ProWritingAid grammar checker, style editor, and editing tool (https://prowritingaid.com/Free-Online-Collocations-Dictionary. aspx). Finally, Ozdic, the online English Collocation Dictionary, which is based on the British National Corpus and includes over 150,000 collocations, is also a useful tool for showing multi-word constructions. 


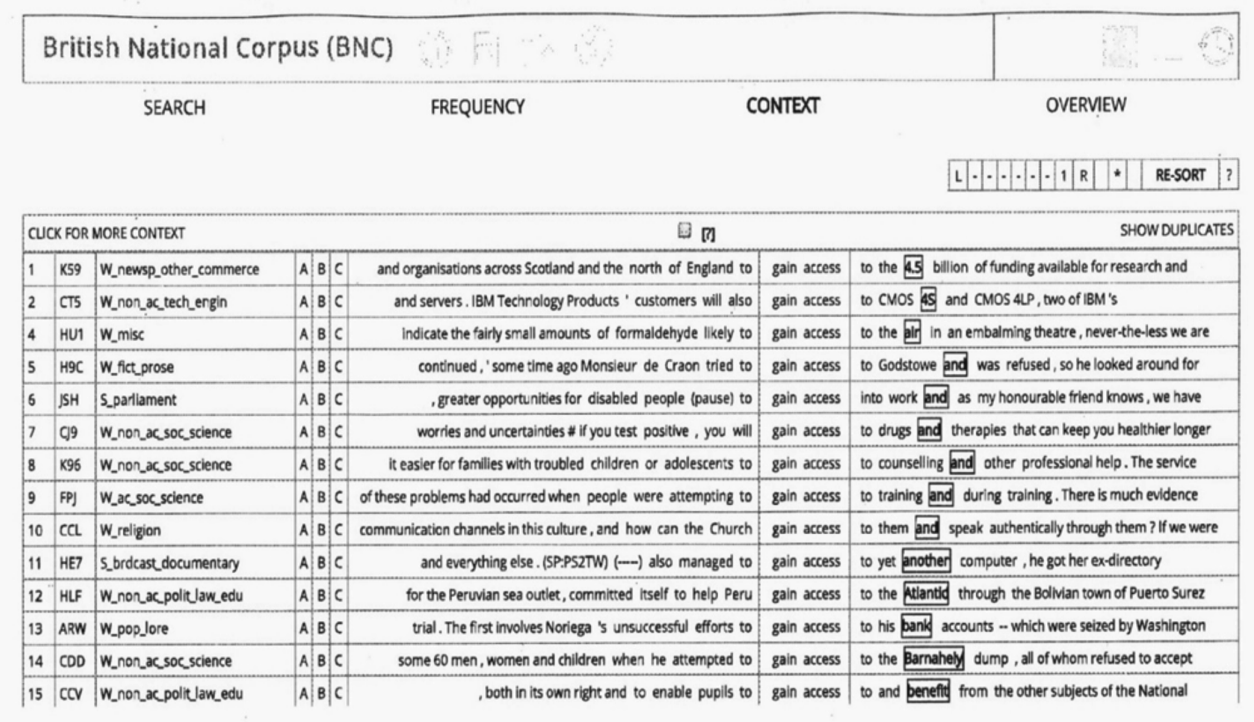

Figure 3. The KWIC display of the collocation gain access in the BNC

\section{Conclusions}

The acquisition of collocations is often neglected in EFL classes due to the fact that language coursebooks tend not to discuss them in detail. The paper points out the necessity of teaching collocations in foreign language classes by complementing the usual teaching materials with additional learning resources. It advocates the idea that students should be made aware of the existence of collocations as constructions (acknowledging them in their entirety) and have the opportunity to notice their use in a larger context containing authentic language use. Besides the type of exercises described above, reading and listening tasks on collocations also improve students' vocabulary and facilitate the acquisition process of collocations. Despite the fact that the paper has not dealt with their role in vocabulary practices, they contribute significantly to vocabulary development and the acquisition of word combinations (collocations) as well. 


\section{References}

Bahns, Jens-Moira Eldaw. 1993. Should we teach EFL students collocations? System 21(1): 101-114.

Begagić, Mirna-Vildana Dubravac. 2014. Foreign Language Learners' Collocational Competence. Paper presented at the $5^{\text {th }}$ International Conference Cultural Identity in Digital Era, Faculty of Philosophy, University of Zenica, Zenica.

Benson, Morton-Evelyn Benson-Robert Ilson. 1986. The BBI Combinatory Dictionary of English: A Guide to Word Combinations. Amsterdam/ Philadelphia: John Benjamins.

Boers, Frank-Seth Lindstromberg-June Ecykmans. 2014. Some explanations for the slow acquisition of L2 collocations. Vigo International Journal of Applied Linguistics 11: 41-62.

Bybee, Joan. 2002. Phonological evidence of exemplar storage of multiword sequences. Studies in Second Language Acquisition 2: 215-221.

Demir Cüneyt. 2017. Lexical collocations in English: A comparative study of native and non-native scholars of English. Journal of Language and Linguistic Studies 13(1): 75-87.

Durrant, Phil-Norbert Schmitt. 2010. Adult learners' retention of collocations from exposure. Second Language Research 26(2): 163-188.

Ellis, Rod. 1997. Second Language Acquisition. Oxford: Oxford University Press. Faghih E.-Mahboubeh Sharafi. 2006. The impact of collocation on Iranian EFL learners' interlanguage. Journal of Humanities 16(58): 5-23.

Fan, May. 2009. An exploratory study of collocational use by ESL students - A task-based approach. System 37: 110-123.

Firth, John. 1957. Papers in Linguistics, 1934-1951. London: Oxford University Press.

Hill, Jimmie. 2000. Revising priorities: From grammatical failure to collocational success. In Michael Lewis (ed.), Teaching Collocation: Further Developments in the Lexical Approach, 47-67. Hove: LTP.

Hoey, Michael. 1991. Patterns of Lexis in Text. Oxford University Press.

Goldberg, Adele. 1995. A Construction Grammar Approach to Argument Structure. Chicago: The University of Chicago Press.

- 1997 The relationships between verbs and constructions. In Verspoor, MarjolijnLee Kee Dong-Eve Sweetser (eds), Lexical and Syntactical Constructions and the Construction of Meaning, 383-399. Amsterdam/Philadelphia: John Benjamins.

- 2006. Constructions at Work. Oxford: Oxford University Press.

Keshavarz, Mohammad Hossein-Hossein Salimi. 2007. Collocational competence and cloze test performance: A study of Iranian EFL learners. International Journal of Applied Linguistics 17(1): 81-92. 
Kjellmer, Göran. 1991. A mint of phrases. In Karin Aijmer-Bengt Altenberg (eds), English Corpus Linguistics. Studies in Honour of Jan Svartvik, 111-127. London, New York: Longman.

Laufer, Batia-Tina Waldman. 2011. Verb-noun collocations in second-language writing: A corpus analysis of learners' English. Language Learning. A Journal of Research in Language Studies 61(2): 647-672.

Leech, Geoffrey. 1974. Semantics: The Study of Meaning. Harmondsworth: Penguin Books.

Lewis, Michael. 2000. Language in the lexical approach. In Michael Lewis (ed.), Teaching Collocation: Further Developments in the Lexical Approach, 126155. London: Language Teaching Publications.

Li, Jie-Norbert Schmitt. 2010. The development of collocations use in academic texts by advanced L2 learners: A multiple case study approach. In David Wood (ed.), Perspectives on Formulaic Language: Acquisition and Communication, 23-46. London/New York: Continuum.

McCarthy, Michael. 1998. Spoken Language and Applied Linguistics. Cambridge: Cambridge University Press.

McKeown, Kathleen R.-Dragomir R. Radev. 2000. Collocations. In Robert Dale-Herbert Moisl-Harold Somers (eds), A Handbook of Natural Language Processing, 507-523. New York: Marcel Dekker.

Nekrasova, M. Tatiana. 2009. English L1 and L2 speakers' knowledge of lexical bundles. Language Learning 59(3): 647-686.

Palmer, E. Harold. 1954. A Grammar of English Words. London: Longmans Green and Co.

Palmer, Frank Robert. 1976. Semantics: A New Outline. Cambridge: Cambridge University Press.

Ramirez, Amelia Torres. 2012. The lexical approach: Collocability, fluency and implications for teaching. Revista de lenguas para Fines Específicos 18: 237-254.

Schmid, Hans-Jörg. 2003. Collocations: Hard to pin down, but bloody useful. Zeitschrift für Anglistik und Amerikanistik 51(3): 235-258.

Schmidt, Richard. 2001. Attention. In Peter Robinson (ed.), Cognition and Second Language Instruction, 3-32. Cambridge: Cambridge University Press.

Schmitt, Norbert. 2000. Vocabulary in Language Teaching. Cambridge: Cambridge University Press.

Sinclair, John. 1991. Corpus, Concordance, Collocation. Oxford: Oxford University Press.

Sung, J. 2003. English Lexical Collocations and Their Relation to Spoken Fluency of Adult Non-Native Speakers. Unpublished doctoral dissertation. Indiana University of Pennsylvania, Pennsylvania.

Taylor, John R. 2017. Lexical Semantics. In Barbara Dancygier (ed.), The Cambridge Handbook of Cognitive Linguistics. Cambridge: Cambridge University Press. 
Thornbury, Scott. 2002. How to Teach Vocabulary. London: Longman.

Waller, Tove. 1993. Characteristics of near-native proficiency in writing. In Hakan Ringbom (ed.), Near-Native Proficiency in English, 183-293. Finland: Abo Akademi.

Wray, Alison. 2002. Formulaic Language and the Lexicon. Cambridge: Cambridge University Press.

Yamashita, Junko-Nan Jiang. 2010. L1 influence on the acquisition of L2 collocations: Japanese ESL users and EFL learners acquiring English collocations. TESOL Quarterly 44(4): 647-668.

Zhang, Xiaolin. 1993. English Collocations and Their Effect on the Writing of Native and Non-Native College Freshmen. Pennsylvania: Indiana University of Pennsylvania.

\section{Books with exercises on collocations:}

Marks, Jon-Alison, Wooder. 2007. Check Your Vocabulary for Natural English Collocations. London: A\&C Black Publishers.

McCarthy, Michael-Felicity, O’Dell. 1999. English Vocabulary in Use:Elementary, Cambridge University Press.

- 2008. English Collocations in Use: Advanced. Cambridge University Press.

Oliveira, Shayna 2003. 1000 English Collocations in 10 Minutes a Day. https://vk.com/doc2603620_443968436?hash=e26c890e53d982b059\&dl=ff14 10487708 ec0017 (Last accessed: 20 May 2019).

\section{Analysed books:}

Clive Oxenden-Christina Latham-Koenig. 1997a. New English File: Beginner: Student's Book, OUP.

- 1997b. New English File: Intermediate: Student's Book, OUP.

— 1997c. New English File: Upper-Intermediate: Student's Book, OUP.

- 1997d. New English File: Advanced: Student's Book, OUP.

Clive Oxenden-Christina Latham-Koenig-Jane Hudson. 1997a. New English File: Upper-Intermediate: Workbook, OUP.

- 1997b. New English File: Advanced: Workbook, OUP.

Clive Oxenden-Christina Latham-Koenig-Paul Seligson. 1997a. New English File: Elementary: Student's Book, OUP.

— 1997b. New English File: Pre-Intermediate: Student's Book, OUP.

— 1997c. New English File: Pre-Intermediate: Workbook, OUP.

- 1997d. New English File: Intermediate: Workbook, OUP.

Clive Oxenden-Christina Latham-Koenig-Paul Seligson-Jane Hudson. 1997. New English File: Elementary: Workbook, OUP. 